\title{
Chemical and mechanical stability of air annealed cathodic arc evaporated CrAION coatings
}

Eluxka Almandoz ${ }^{1}$, Gonzalo. G. Fuentes ${ }^{1 *}$, José Fernández ${ }^{1}$, Javier Martínez de Bujanda ${ }^{1}$, Rafael J. Rodríguez-Trías ${ }^{2}$

Fco. Javier Pérez-Trujillo ${ }^{3}$, Germán Alcalá ${ }^{3}$, Arturo Lousa ${ }^{4}$, Yi Qin ${ }^{5}$

${ }^{1}$ Center of Advanced Surface Engineering, AIN. Cordovilla-Pamplona E3119. Spain

${ }^{2}$ Universidad Pública de Navarra, Campus Arrosadía Pamplona E31006. Spain

${ }^{3}$ Grupo de Ingeniería de Superficies y Materiales Nanoestructurados $N^{\circ} 910627$, Universidad

Complutense de Madrid, Facultad de Ciencias Químicas, E-28040 Madrid, Spain.

${ }^{4}$ Departamento de Física Aplicada y Óptica, Universidad de Barcelona, E08028 Barcelona, Spain

${ }^{5}$ Dept. of Design, Manufacture and Engineering Management, The University of Strathclyde, G1 1XJ Glasgow, UK

\section{*corresponding author}

Address: Center of Advanced Surface Engineering, AIN. Carretera de Pamplona, 1. Cordovilla; E31191-Spain

e-mail: gfuentes@ain.es

Tfn: + 34948421190

Fax: + 34948421100 


\section{Abstract}

This study reports the synthesis and characterization of ternary $\mathrm{Cr}-\mathrm{Al}-\mathrm{O}$ and quaternary $\mathrm{Cr}-$ Al-O-N coatings deposited by cathodic arc physical vapour deposition, for various nitrogen and oxygen mass flow ratios during the growth process. The composition, microstructure, indentation hardness and modulus of the films have been characterized by scanning electron microscopy, electron probe micro-analysis, X-ray diffraction, and nanoindentation techniques. The evolution of the microstructure and mechanical properties of the coatings after ambient air annealing from $800^{\circ} \mathrm{C}$ up to $1100^{\circ} \mathrm{C}$ have been investigated. As the oxygen to nitrogen mass flow increases, the as-deposited coatings exhibit lower hardness, higher roughness, lower crystallinity and a more marked columnar structure. At oxygen to nitrogen mass flow ratios bigger than $10 / 90$, the coatings exhibit a stoichiometry of the type $(\mathrm{CrAl})_{2+\varepsilon} \mathrm{O}_{3-\varepsilon}$. Only the coatings with an oxygen to nitrogen mass flow ratio smaller than 10/90 retained nitrogen in their compositions. In all cases, the coatings developed a cubic fcc lattice structure. After annealing at $1100{ }^{\circ} \mathrm{C}$ the resulting microstructure showed a clear dependency upon the initial composition of the films. The evolution of the microstructure during the high temperature tests, as well as the analysis of the nanoindentation hardness, composition and thickness also provided valuable information about the combined effects of the thermal stability and the oxidation of the deposited coatings.

\section{Keywords: CrAION coatings, wear, cathodic arc evaporation, thermal stability}




\section{Introduction}

Physical Vapour Deposition (PVD) of ternary Cr-Al-O and quaternary Cr-Al-O-N coating formulations have received a particular attention from the tooling and metal component industries due to its potential to attain the mechanical properties of super hard materials such as corundum $\alpha-\mathrm{Al}_{2} \mathrm{O}_{3}[1-6]$. The idea is based on the capability of the eskolaite $\left(\alpha-\mathrm{Cr}_{2} \mathrm{O}_{3}\right)$ crystalline structure to act as a template for the growth of the corundum phase $\alpha-\mathrm{Al}_{2} \mathrm{O}_{3}$, at temperature ranges permitting the deposition on tool steels, i.e. typically $450^{\circ} \mathrm{C}-550^{\circ} \mathrm{C}[2-7]$. All this is feasible because of two main reasons; the structure of eskolaite $\alpha-\mathrm{Cr}_{2} \mathrm{O}_{3}$ has the same space group as corundum $\alpha-\mathrm{Al}_{2} \mathrm{O}_{3}$, and on the other hand the eskolaite $\alpha-\mathrm{Cr}_{2} \mathrm{O}_{3}$ can be synthesized at the application working temperatures of tool steels. In this context, two different approaches have been considered using PVD techniques in order to exploit these properties. The first one is focussed on the development of routes to deposit $\alpha-\mathrm{Al}_{2} \mathrm{O}_{3}$ based coatings by predeposition of $\alpha-\mathrm{Cr}_{2} \mathrm{O}_{3}$ template films [2,7]; while the second consists on the deposition of $\alpha$ $(\mathrm{CrAl})_{2} \mathrm{O}_{3}$ strengthened solid solutions by co-evaporation of $\mathrm{Cr}$ and $\mathrm{Al}$ in the presence of oxygen [8-11].

At temperatures compatible with the working conditions of hot forming steels, the eskolaite/corundum equilibrium phase diagram shows a wide miscibility gap, which theoretically restricts the formation of solid solutions to only a small mass percentage of $\mathrm{Al}$ in eskolaite or $\mathrm{Cr}$ in corundum [12]. Different studies reveal that a variety of phases can be attained for the system Cr-Al-O, and Cr-Al-O-N, including solid solutions. For example, Pedersen et al [8] and Dietchler et al [4] reported the formation of solid solutions in the form of $\alpha-\left(\mathrm{Al}_{1-\mathrm{x}}, \mathrm{Cr}_{\mathrm{x}}\right)_{2} \mathrm{O}_{3}$ in d.c. 
and r.f. sputtered $\mathrm{Cr}-\mathrm{Al}-\mathrm{O}$ films. Khatibi et al $[5,13]$ studied the system $\left(\mathrm{Al}_{\mathrm{x}} \mathrm{Cr}_{1-\mathrm{x}}\right)_{2+\mathrm{y}} \mathrm{O}_{3-\mathrm{y}}$ for various deposition conditions using sputtering and cathodic arc evaporation. Firstly, they found that the films with stoichiometry $\left(\mathrm{Al}_{1-\mathrm{x}}, \mathrm{Cr}_{\mathrm{x}}\right)_{2} \mathrm{O}_{3}$ could develop fcc cubic lattice structures [5] with $33 \%$ cation vacancies under certain deposition conditions. In a follow-up study [13] the authors found that the films developed corundum or mixed-phases depending on both, the $\mathrm{Cr} / \mathrm{Al}$ ratio and the oxygen gas flow. Thus, the corundum phase was favoured at high $\mathrm{Cr}$ content and at high $\mathrm{O}_{2}$ flows, while the cubic fcc phase was observed for high $\mathrm{Al}$ content and low $\mathrm{O}_{2}$ flow per active target. Najafi et al [9] found that the lattice structure of arc evaporated coatings Cr-Al-O could dynamically evolve from a fcc cubic crystalline structure to a rhombohedral $\alpha-(\mathrm{CrAl})_{2} \mathrm{O}_{3}$ during the deposition process when the coating thickness exceeded to 2 microns. Ramm et al [11] developed different coating microstructures and compositions based on pulsed electron emission arc evaporation of $\mathrm{Cr} / \mathrm{Al}$ cathodes in oxygen atmospheres. Essentially, they showed that the produced coatings developed corundum-like lattice structure forming a solid solution of the type $\left(\mathrm{Al}_{1-\mathrm{x}} \mathrm{Cr}_{\mathrm{x}}\right)_{2} \mathrm{O}_{3}$.

The influence of nitrogen as the reactive gas during the deposition of Cr-Al-O films has also been investigated [1,14-17]. For example, Hirai et al. [1] reported on CrAlON coatings synthesized by pulsed laser deposition at a substrate temperature of $400{ }^{\circ} \mathrm{C}$, obtaining fcc cubic structures with a metal non-metal ratio of 1, and similar oxygen and nitrogen contents of 25 at.\%. Najafi et al [14] reported on cathodic arc deposited $\mathrm{AlCr}\left(\mathrm{O}_{\mathrm{y}} \mathrm{N}_{1-\mathrm{y}}\right)$ coatings using rotary pulsed $\mathrm{Cr} / \mathrm{Al}$ targets in an oxygen and nitrogen atmosphere. They observed films with three different microstructures depending on the oxygen to nitrogen content. For $y<0.6$, a well-defined columnar fcc cubic lattice structure was found. For $0.6<\mathrm{y} \leq 0.97$, the fcc lattice structure was 
still present but the columnar morphology diffused. This cubic structure was explained in terms of the presence of cation vacancies, as reported by Khatibi et al.[5] for sputtered $\left(\mathrm{Al}_{1-\mathrm{x}} \mathrm{Cr}_{\mathrm{x}}\right)_{2} \mathrm{O}_{3}$ films. In the case of $y>0.97$, the main lattice phase was a corundum $\alpha-(\mathrm{CrAl})_{2} \mathrm{O}_{3}$ solid solution. By adding nitrogen to r.f. sputtered Cr-Al-O films, Stüber et al [16] found that fcc cubic lattice structures could only be formed when the relative nitrogen gas flow $\left(\Delta N_{\text {rel }}\right.$ in $\left.\%\right)$ over the total $\left(\mathrm{O}_{2}+\mathrm{N}_{2}\right)$ is larger than the $75 \%$, with a relatively small dependence on the $\mathrm{Al} / \mathrm{Cr}$ ratio. The stoichiometry of the films with $\Delta N_{\text {rel }}$ above $75 \%$ corresponded to a formulation of the form $\left(\mathrm{Al}_{1-\mathrm{x}} \mathrm{Cr}_{\mathrm{x}}\right)_{1+\theta}\left(\mathrm{O}_{1-\mathrm{y}} \mathrm{N}_{\mathrm{y}}\right)$ and a fcc cubic phase, whereas below this threshold they resemble the form $\alpha-\left(\mathrm{Al}_{1-\mathrm{x}} \mathrm{Cr}_{\mathrm{x}}\right)_{2+\delta}\left(\mathrm{O}_{1-\mathrm{y}} \mathrm{N}_{\mathrm{y}}\right)_{3}$, showing a corundum-like structure.

From the technological point of view, various authors have investigated the effect of oxygen in reactive arc deposition for $(\mathrm{Al}, \mathrm{Cr})_{2} \mathrm{O}_{3}$ films using arc industrial systems [3,10,11]. Pohler et al [10] found that the cathode developed selective poisoning forming pillar-shaped $\mathrm{Al}_{2} \mathrm{O}_{3}$ islands and intermetallic $\mathrm{Al}_{\mathrm{x}} \mathrm{Cr}_{\mathrm{y}}$ phases with a fine-grained morphology during the process. This can also reduce the ion current obtained per cathode $[3,18]$, as oxygen replaces nitrogen in the reactor chamber.

The thermal stability of Cr-Al-O and Cr-Al-O-N coatings has also been addressed in different studies. Khatibi et al [13] showed that in-situ heat treatments of pristine fcc- $\left(\mathrm{Al}_{0.83} \mathrm{Cr}_{0.17}\right)_{2.3} \mathrm{O}_{2.7}$ leads to the transformation to a corundum structure, which initiates at $900{ }^{\circ} \mathrm{C}$ and is totally completed at temperatures above $1000{ }^{\circ} \mathrm{C}$. In the case of films with an original corundum structure in the as-deposited state, thermal annealing did not lead to any structural modifications up to $1100^{\circ} \mathrm{C}$. Similar results were found by Edlmayr et al [19] on vacuum, and by Najafi et al 
[14] on argon annealed arc deposited coatings. Hirai et al. [1] reported that the fcc cubic structure of laser deposited Cr-Al-O-N remains after oxidation in air up to $1100{ }^{\circ} \mathrm{C}$.

Other studies focused on multilayered systems for oxidation and corrosion protection of bipolar plates, and high temperature Mo-based sintering tools [20, 21]. More recently Liu et al [22] investigated the thermal stability of arc deposited $\mathrm{AlCrON}$ and $\mathrm{AlCrO}$ interlayers in solar selective stacks up to $800^{\circ} \mathrm{C}$, showing barely any structural modification. Some formulations have been tested under friction [23] and machining operations [13], showing different performances in comparison to industrial coating formulations. Bobzin et al. [24] deposited thick $\mathrm{CrAlO}$ and $\mathrm{CrAlON}$ using high-speed deposition sputtering. The influence of the bias has also been reported, in particular the effects of bipolar pulsing and duty cycle CAE deposited CrAlFeO and $\mathrm{CrAlO}$ arc coatings $[25,26]$.

In this work, the combined effect of temperature and oxidation in the films are discussed in terms of the evolution of the stoichiometry, crystalline phases and the mechanical properties; from the as deposited state, up to air annealing temperatures of $1100^{\circ} \mathrm{C}$.

\section{Experimental}

The CrAlON coatings have been produced by cathodic arc evaporation, using a commercial PVD reactor able to reach a base pressure of $2-4 \times 10^{-4} \mathrm{~Pa}$. The reactor is equipped with two opposing columns, each one of them hosting three circular cathodes (63 $\mathrm{mm}$ of diameter) 
vertically aligned. Both columns face each other and leave an effective volume of $0.1 \mathrm{~m}^{3}$ available for the substrates. Both columns were equipped with high purity $\mathrm{CrAl}$ cathodes, with a nominal composition of $\mathrm{Cr} 50$ at. $\%$ - $\mathrm{Al} 50$ at. \%. The substrates were martensitic quenched hot work $\mathrm{H} 13$ steel tempered at $520^{\circ} \mathrm{C}(53-55 \mathrm{HRc})$ at the zone of secondary tempering hardness, commonly used for high pressure Al die casting; with a nominal composition of 0.4 at $\% \mathrm{C}, 0.9$ at $\% \mathrm{Si}, 0.3$ at $\% \mathrm{Mn}, 5.43$ at $\% \mathrm{Cr}, 1.32 \mathrm{at} \% \mathrm{Mo}$, and 0.96 at $\% \mathrm{~V}$. Discs of $40 \mathrm{~mm}$ in diameter were mirror polished $(\mathrm{Ra}<15 \mathrm{~nm})$ and cleaned in an ultrasonic bath using de-oiling agents and de-ionised water. In addition, $\mathrm{Si}$ and INCONEL substrates were used to deposit the coatings for subsequent SEM analyses and thermal stability tests.

The substrates were vacuum-heated and $\mathrm{Ar}^{+}$-ion bombarded using the so-called Arc Enhanced Glow Discharge (AEGD) process. After the $\mathrm{Ar}^{+}$-ion bombardment, high purity nitrogen and oxygen gases were mixed in the chamber to produce seven different coatings (A-G), which composition and structure varied as a function of the $\mathrm{O}_{2} / \mathrm{N}_{2}$ mass flow ratio introduced in the chamber during the deposition process. In all the cases, the working pressure was kept at $1.8 \mathrm{~Pa}$. A continuous DC bias of $-50 \mathrm{~V}$ was applied on the substrates, except for the eighth sample batch (H) which was deposited using a bias of $-200 \mathrm{~V}$. During the whole process, the substrates were rotated around the central vertical axis of the reactor chamber at a speed of $5 \mathrm{rpm}$. A CrAlN adhesion layer of around 0.2 microns thick was deposited in all the batches prior to the production of the investigated coatings. The substrates were set to $410-430^{\circ} \mathrm{C}$ range during deposition, as estimated from Rockwell $\mathrm{C}$ hardness measurements on the back side of hardened $100 \mathrm{Cr} 6$ bearing steel discs placed in the chamber during the process, fine-grained polished and 
finally tested. The results were compared with their tempering curves as described elsewhere [27]. Table 1 summarises the coating deposition parameters used in this work.

The chemical composition of the coatings was determined using an electron probe microanalyser (EPMA, JEOL JXA 8900m) using a wavelength-dispersive spectrometer (WDS). Before the observation of the coatings' surface, as a standard procedure the samples were coated with graphite, using a Quorum Q150T evaporator, to ensure electrical conductivity. X-ray diffraction (XRD) analyses were carried out in a BRUKER-D8 spectrometer using the parallel beam configuration, a $\mathrm{Cr}$ X-ray source (lambda $=0.22897 \mathrm{~nm}$ ) and a grazing angle of $1^{\circ}$. A field emission scanning electron microscope (SEM) HITACHI S- was used to inspect the cross sections of the films.

Nanoindentation tests were performed on the as-deposited samples using a Hysitron Triboindenter ${ }^{\odot} 950$ system fitted with a Berkovich indenter with a tip-end radius of around 150 nm. Forty indentations, separated enough to avoid influence from each other measurements were made on all the specimens using a peak load of $5 \mathrm{mN}$. The load function consisted on a 5 seconds loading segment, followed by a 2 seconds holding load to account for the material creep response. A last 5 seconds unloading segment concluded each test.

The Oliver and Pharr method [28] was used to obtain the hardness and Young's modulus values from the experimental load-displacement curves. At $5 \mathrm{mN}$ load, the maximum penetration of the indenter in the surface was clearly below the $10 \%$ of the total thickness of the coating, value widely accepted to measure the mechanical properties of a layer with no interference from the 
substrate [29]. Surface roughness was measured with a WYCO-RST 500 profilometer using the vertical scanning interferometry (VSI) mode. This system provides a vertical resolution of $3 \mathrm{~nm}$.

High temperature annealing tests in ambient air were carried out in a Nabertherm LT 24/11/B180 muffle oven from $800{ }^{\circ} \mathrm{C}$ up to $1100{ }^{\circ} \mathrm{C}$ in steps of $100^{\circ} \mathrm{C}$. A heating rate of $20^{\circ} \mathrm{C} \cdot \mathrm{min}^{-1}$ and a holding time of 2 hours was used for each step, followed by natural oven cooling after the holding period of the last step. Nanoindentation tests and SEM-EDX analyses were carried out subsequent to the high temperature annealing tests.

\section{Results}

\subsection{Composition and microstructure as deposited}

Table 2 shows the chemical composition and the thicknesses of the Cr-Al-O-N coatings, obtained by the EPMA analyses, as a function of the $\mathrm{O}_{2} / \mathrm{N}_{2}$ gas flow ratio. The samples in batch A, deposited using a gas flow ratio of $0 / 100$, exhibit the composition of a substoichiometric

$\operatorname{CrAlN}_{\mathrm{x}}(\mathrm{x}<1)$, with a small residual amount of oxygen around $2 \mathrm{at} \%$. The increase of the $\mathrm{O}_{2} / \mathrm{N}_{2}$ gas flow ratio leads to an increase in the oxygen content of the coatings. Samples in group B (5/95) show an oxygen content of 30 at $\%$, whereas the nitrogen content decreases to 22 at $\%$. Batches $\mathbf{C}$ to $\mathbf{H}$, deposited using gas flow ratio from 10/90 on, present no nitrogen in their composition, whilst their oxygen content is larger than 57 at $\%$ for all of them. The $\mathrm{Cr} / \mathrm{Al}$ ratio is nearly constant for all the deposited coatings and close to unity, in line with the nominal composition of the cathodes. In addition, the thickness of the deposited coatings decreases as the 
$\mathrm{O}_{2} / \mathrm{N}_{2}$ gas flow ratio increases, in agreement to Khatibi et al [15]. This is likely due to the effect of increasing oxidation of the arc targets surfaces during deposition, since a larger amount of oxygen is present in the vacuum chamber.

Table 2 also displays the cation to anion ratio $(\mathrm{Cr}+\mathrm{Al})_{1-\mathrm{x}} /(\mathrm{O}+\mathrm{N})_{\mathrm{x}}$ in the form of the parameter $\boldsymbol{x}$. Whereas samples in batch $\mathbf{A}$ exhibit a $\boldsymbol{x}$ factor of $36 \%$, it rises as the $\mathrm{O}_{2} / \mathrm{N}_{2}$ gas flow ratio increases. Particularly, specimens in batch $\mathbf{B}$ (oxynitrides) present an $\boldsymbol{x}$ factor of $52 \%$, increasing to around $61-62 \%$ for batches $\mathbf{C , ~} \mathbf{D}$ and $\mathbf{F}$, and slightly decreasing down to $57-58 \%$ for batches $\mathbf{G}$ and $\mathbf{H}$. The samples in batches $\mathbf{C}$ to $\mathbf{H}$ clearly show that the cation to anion ratio approaches $2 / 3$ as the $\mathrm{O}_{2} / \mathrm{N}_{2}$ gas flow ratio increases. This means that the stoichiometric formulae of the pure oxide coatings, i.e. not containing nitrogen to the detection limit of EPMA, exhibit the form $(\mathrm{CrAl})_{2+\varepsilon} \mathrm{O}_{3-\varepsilon,}$, with $\varepsilon$ typically smaller than 0.3 . On the other hand, batches $\mathbf{A}$ and $\mathbf{B}$ (both oxynitrides) respond to a stoichiometric formula $(\mathrm{CrAl})_{1-\mathrm{x}}(\mathrm{NO})_{\mathrm{x}}$, with the indication that samples in batch $\mathbf{A}$ are substoichiometric.

Figures 1 a-h show the cross section SEM micrographs of the coatings $\mathbf{A}$ to $\mathbf{H}$ respectively, as deposited on the Si substrates, as recorded with the secondary electron detector. The microstructure of the coatings shows some dependence on the $\mathrm{O}_{2} / \mathrm{N}_{2}$ gas flow ratio. The cross sections also reveal the initial stages of film growth starting from the CrAlN 0.2 microns adhesion layer. Specifically, the coatings $\mathbf{A}$ to $\mathbf{E}$ present a dense microstructure consisting of compacted micro-columns growing perpendicular to the substrate. This microstructure is common in arc PVD coatings based on $\mathrm{Ti}$ and $\mathrm{Cr}$ nitrides [30]. Contrarily, the coatings $\mathbf{F}$ and $\mathbf{G}$ exhibit a less compact microstructure, likely caused by instabilities of the cathode due to the 
oxidation of its surface in the presence of Oxygen [3]. The $\mathbf{H}$ films, show a compact structureless cross section, probably caused by the larger bias used for its deposition (-200 V).

Figure 2 shows the grazing angle XRD patterns of the as deposited coatings as a function of the $\mathrm{O}_{2} / \mathrm{N}_{2}$ gas flow. Samples in $\mathbf{A}(0 / 100)$ show reflections at $58.0^{\circ}, 68.1^{\circ}$ and $104.7^{\circ}$ attributed to the lattice planes (111), (200) and (220) of a fcc-NaCl like lattice structure (indicated as $\otimes$ ). The peaks are slightly shifted to higher angles with respect to the positions expected for the $\mathrm{CrN}$. This is due to the substitution by Al of the Cr-cation in the lattice. A low angle shoulder at the peak (200) could be attributed to diffraction of hexagonal $\beta-\mathrm{Cr}_{2} \mathrm{~N}$ phases. The specimens in batch $\mathbf{A}$ also show diffraction peaks at $49.3^{\circ}, 92.5^{\circ}$ and $107.4^{\circ}$, assigned to hexagonal forms of AlN (•). Specimens in B show a similar structure to that of batch A. This is apparently coherent with the stoichiometric formulation for these samples (cf. Table 2$)$, of the form $(\mathrm{CrAl})_{1-\mathrm{x}}(\mathrm{NO})_{\mathrm{x}}$, provided that in this case oxygen is replacing nitrogen at anionic sites. The peak (220) of samples in batch $\mathbf{B}$ shows a shoulder at the large $2 \theta$ side, which can be attributed to the reflection (103) of h-AlN. In fact, this peak shoulder can also be inferred in sample $\mathbf{A}$, although with less intensity.

In the case of the samples $\mathbf{C}$ to $\mathbf{H}$, a new diffraction feature is observed at $66.0^{\circ}(\diamond)$, which has no correspondence with any feature observed for the samples in $\mathbf{A}$ or $\mathbf{B}$. In addition, the peaks at $68.8^{\circ}$ and $107.3^{\circ}$ observed for the specimens in $\mathbf{C}$ to $\mathbf{H}$, can be assigned to the planes (200) and (220) respectively of a fcc cubic lattice of chromium-aluminium oxide, with a stoichiometric formulation like $(\mathrm{CrAl})_{2+\varepsilon} \mathrm{O}_{3-\varepsilon}$, as found by other authors $[5,9,13,14]$. This phase was described by [5] as a face centred cubic lattice with $33 \%$ cation vacancies. These fcc peaks appear slightly shifted to higher angles with respect to these of samples in $\mathbf{A}$ and $\mathbf{B}$. 
In order to get more information about the evolution of the observed cubic phases, we have represented in Figure 3 the lattice parameter a obtained from the positions of the assigned fcc(220) diffraction planes, as a function of the oxygen mass flow percentage during deposition (cf. Table 2). The a a value obtained for the samples in $\mathbf{A}$ is $0.408 \mathrm{~nm}$. As the $\% \mathrm{O}_{2}$ gas flow increases to $25 \%$, the lattice parameter decreases to $0.403 \mathrm{~nm}$, and keep this value for bigger $\% \mathrm{O}_{2}$ gas flow values. Khatibi et al [5] reported a lattice parameter value of $0.404 \mathrm{~nm}$ for the cubic fcc$(\mathrm{CrAl})_{2} \mathrm{O}_{3}$ phase, in good agreement with our results.

On the other hand, the diffraction peak at $66.0^{\circ}$ lays within the expected range for the reflections of rhombohedral $\alpha-\mathrm{Cr}_{2} \mathrm{O}_{3}$ (eskolaite) and/or $\alpha-\mathrm{Al}_{2} \mathrm{O}_{3}$ (corundum). This peak has been identified by various authors $[1,3,4,9]$. However, there are other possible crystallographic plains that may produce diffractions near this $2 \theta$ position, such as $\mathrm{Al}_{4} \mathrm{Cr}$ or $\mathrm{Al}_{8} \mathrm{Cr}_{5}$ intermetallics, which may appear on the coatings from cathode ejected and unreacted droplets. The fact that the rhombohedral structures do not predominate in the diffraction peaks of the coatings, as deposited, can be due to the deposition temperature of $430^{\circ} \mathrm{C}$, which is lower than that reported for such phases to grow stably [2-7].

\subsection{Roughness and mechanical properties}

Table 3 gathers the roughness parameters $\mathrm{Ra}$ and $\mathrm{Rq}$, the indentation hardness and elastic modulus of the produced coatings. The Ra values of samples in batches $\mathbf{A}$ and $\mathbf{C}$ are around 55 and $47 \mathrm{~nm}$. These values are typical for arc evaporated coatings with Al content [30,31]. Batches 
$\mathbf{D}$ to $\mathbf{H}$ exhibit $\mathrm{Ra} / \mathrm{Rq}$ values doubling these shown by $\mathbf{A}-\mathbf{C}$ specimens. This can be attributed to the fact that, when the $\mathrm{O}_{2} / \mathrm{N}_{2}$ gas flow increases the target surface oxidises. This causes the arcs to discharge on smaller target areas, rather than dispersing across its available area, thus producing the ejection of bigger particles $[3,11]$. The oxidation of the target as the $\mathrm{O}_{2} / \mathrm{N}_{2}$ gas flow increases is also in agreement with the observed decrease in the observed deposition rate.

Figure 4 show the nanoindentation hardness and reduced modulus of the coatings as a function of the $\mathrm{O}_{2} / \mathrm{N}_{2}$ gas flow, for the samples $\mathbf{A}$ to $\mathbf{H}$. The batch $\mathbf{A}$ coatings have a nanoindentation hardness of $23.3 \mathrm{GPa}$ and a reduced modulus of $202 \mathrm{GPa}$. These values are lower than others measured for CrAlN coatings [31], due to the low nitrogen content and to the presence of some volume fraction of h-AlN and $\beta-\mathrm{Cr}_{2} \mathrm{~N}$ phases as observed by XRD. The $\mathbf{B}$ specimens exhibit a larger hardness than that of batch $\mathbf{A}$ (i.e. $28.8 \mathrm{GPa}$ ) and smaller rigidity $(187 \mathrm{GPa})$. This increase can be caused either by the smaller ratio of anion vacancies, or to a solid solution strengthening effect. For the rest of the samples, i.e. as $\mathrm{O}_{2} / \mathrm{N}_{2}$ gas flow increases further, there is a progressive decrease of the nanoindentation hardness and modulus. In this study, the hardness evolved from 28.8 GPa for the oxynitride coatings down to $16 \mathrm{GPa}$ for the films deposited using the largest $\mathrm{O}_{2} / \mathrm{N}_{2}$ gas flow ratio. Given that the composition of the samples remains similar (cf. Table 2), this decrease of the mechanical strength may be caused by the loss of compactness of the coating micro-columns and a mayor presence of micro droplets, as observed by SEM. However, batch $\mathbf{H}$ showed a hardness of $26.8 \mathrm{GPa}$, which is clearly larger than that of its twin batch $\mathbf{E}$, though deposited at $-200 \mathrm{~V}$ of bias. This can again be attributed to the more compact microstructure observed by SEM for H samples (cf. Fig 1H). A similar hardness evolution has been reported by Najafi et al. [13]. On the other hand, Stüber et al. [16] found little dependence of the indentation 
hardness as a function of the N/O ratio, which was explained by the formation of vacancies, changes of chemical bonding and the coatings microstructure. Hardness values between $25 \mathrm{GPa}$ and $30 \mathrm{GPa}$ were reported by Khatibi et al. [13], with a slight increase as the $\mathrm{Cr}$ content rose.

\subsection{Composition, hardness and microstructure after annealing in air}

In order to get insight on the thermal stability and oxidation behaviour of these coatings, we have studied the mechanical and structural evolution of various representative samples after annealing in ambient air at temperatures from $700^{\circ} \mathrm{C}$ up to $1100^{\circ} \mathrm{C}$. Figure 5 provides evidence of the different mechanical evolution of the deposited coatings $\mathbf{A}, \mathbf{B}, \mathbf{C}, \mathbf{D}$ and $\mathbf{G}$ after annealing. The measurements indicate an overall increase of all the coatings hardness after annealing at $700{ }^{\circ} \mathrm{C}$ in comparison to the as deposited specimens. Batch $\mathbf{A}$ retains its hardness values or even increases them up to $27 \mathrm{GPa}$ for annealing temperatures at 700 and $800{ }^{\circ} \mathrm{C}$. Its hardness decreases after annealing at $900{ }^{\circ} \mathrm{C}$ and $950{ }^{\circ} \mathrm{C}$, rising again to 26.8 after $1000{ }^{\circ} \mathrm{C}$ and $1050{ }^{\circ} \mathrm{C}$ treatments. Batch $\mathbf{B}$ steadily decreases its hardness as the annealing temperature increases from $800{ }^{\circ} \mathrm{C}$ to $1050{ }^{\circ} \mathrm{C}$, showing a slight increase at $1100{ }^{\circ} \mathrm{C}$. The samples from batch $\mathbf{C}$ retain their hardness values for over the whole range of annealing temperatures, whereas the hardness of samples from $\mathbf{D}$ and $\mathbf{G}$ steadily rises as the annealing temperature increases. The reduced modulus exhibits similar trends to those of the nanoindentation hardness.

Table 4 shows the comparison of the stoichiometry and the thickness of the coatings $\mathbf{A}, \mathbf{B}, \mathbf{C}, \mathbf{D}$ and $\mathbf{G}$ before and after a thermal annealing at $1050{ }^{\circ} \mathrm{C}$. It is noticeable that the coating thicknesses remain nearly around the same values of those as deposited. Meanwhile, the 
stoichiometry of the coatings, expressed in the form $\left(\mathrm{Cr}_{1-\mathrm{x}} \mathrm{Al}_{\mathrm{x}}\right)_{2+\mathrm{y}} \mathrm{O}_{3-\mathrm{y}}$, reflects the influence of the exposition to hot air. The cation ratio $\mathrm{Cr} / \mathrm{Al}$ decreases from 52/48 to $32 / 68$ for the samples from batch $\mathbf{A}$. This fact could be attributed to diffusion of the $\mathrm{Al}$ atoms towards the outer surface of the film [32]. Samples from $\mathbf{B}$ to $\mathbf{G}$ do not show significant changes in the cation ratio $\mathrm{Cr} / \mathrm{Al}$ with respect to those measured in the as deposited specimens. The specimens in $\mathbf{A}$ and $\mathbf{B}$ also show a significant modification of the cation to anion ratio, which evolves from $1 / 0.57$ to 2.23/2.77 for the A samples, and from 0.96/1.04 to 1.98/3.02 in the case of the $\mathbf{B}$ samples. This fact clearly indicates that oxygen completely replaces nitrogen in the lattice after annealing. In contrast, coatings $\mathbf{C}, \mathbf{D}$ and $\mathbf{G}$ annealed at $1050{ }^{\circ} \mathrm{C}$ exhibit no change in their composition after thermal treatment.

Figure 6a compares the diffraction patterns obtained for the batches A (nitride), B (oxynitride), and $\mathbf{C}$ and $\mathbf{D}$ (oxides), after the annealing treatment at $1100{ }^{\circ} \mathrm{C}$. In order to facilitate comparison with the reference phases, the theoretical peak positions of the main reflections of eskolaite (triangle) and corundum (square) have been pointed out in the graph. Fig. 6a evidences the different evolution of the coating microstructures depending on their initial compositions. The diffraction pattern of the A samples clearly exhibits the presence of both eskolaite and corundum. Specifically, the peaks assigned to the rhombohedral lattices planes (012), (104), (110), (113), (024) and (116). Further small diffraction peaks have not been labelled. This indicates that the A samples evolved from a cubic fcc-CrAlN lattice, with some undetermined volume fraction of h-AlN and $\beta-\mathrm{Cr}_{2} \mathrm{~N}$, towards a dual phase eskolaite-corundum. The $\mathbf{B}$ samples also show doublet peaks at the positions of the rhombohedral lattice planes, like in batch $\mathbf{A}$, though the peak located at low angles is predominant with respect to the one at higher angles, 
and in addition its spectral weight is shifted to higher angles. The diffraction peaks of samples $\mathbf{C}$ and $\mathbf{D}$ exhibit single peak structures (rhombohedral), and further their spectral weights are shifted towards high angles.

In order to obtain a more detailed information on the microstructural evolution of the coatings, we have represented in Fig. 6 b-d the diffraction patterns of batches $\mathbf{B}, \mathbf{C}$ and $\mathbf{D}$ respectively, as a function of the annealing temperature, from $800{ }^{\circ} \mathrm{C}$ to $1100^{\circ} \mathrm{C}$. The $\mathbf{B}$ samples (oxynitride) diffraction patterns indicate the appearance of the phase $\beta-\mathrm{Cr}_{2} \mathrm{~N}$ at an annealing temperature of $900^{\circ} \mathrm{C}$. On the other hand, the cubic fcc phases, planes (200) and (220), are present up to $950{ }^{\circ} \mathrm{C}$. In fact, at $950{ }^{\circ} \mathrm{C}$ neither eskolaite nor corundum can be observed any further. At $1000{ }^{\circ} \mathrm{C}$ new peaks from the rhombohedral planes appear close to the eskolaite positions, while at $1100{ }^{\circ} \mathrm{C}$ the area of the eskolaite peaks is much bigger than that of corundum's. It is remarkable that the peak positions of the rhombohedral lattice planes do not shift as the temperature increases. This confirms that the metal $\mathrm{Cr} / \mathrm{Al}$ ratio is not varying within the coating upon the annealing temperature, as also observed by the EPMA measurements presented in Table 4 (at $1050{ }^{\circ} \mathrm{C}$ ).

The specimens in batch $\mathbf{C}(10 / 90)$ exhibit diffraction patters similar to those of the pristine coating for annealing temperatures up to $900^{\circ} \mathrm{C}$. The cubic phase remains even at $1000^{\circ} \mathrm{C}$, as can be inferred from the peak (220) observed at $2 \theta=107^{\circ}$. At $950{ }^{\circ} \mathrm{C}$ new peaks located in between the theoretical positions of eskolaite and corundum show up, corresponding again to the rhombohedral lattice planes (012), (104), (110), (113), (024) and (116), which grow in intensity as the annealing temperature increases. In this case, only one peak per theoretical eskolaitecorundum band is present. Finally, the $\mathbf{D}$ samples (75/25) show a similar evolution as the $\mathbf{C}$ 
samples. Although, the cubic phase of the pristine coating vanishes at a lower temperature (900 ${ }^{\circ} \mathrm{C}$ ) than that for $\mathbf{B}$ and $\mathbf{C}$. Again, the peaks corresponding to the rhombohedral planes appear at $900{ }^{\circ} \mathrm{C}$ and increase in intensities as the temperature rises to $1100^{\circ} \mathrm{C}$. Like for batch $\mathbf{C}$, no peak doublets are observed. The same response observed in batch B is found here for $\mathbf{C}$ and $\mathbf{D}$, the peak positions of the rhombohedral lattice planes do not shift as the temperature increases, in agreement with the non-variation of the metal $\mathrm{Cr} / \mathrm{Al}$ ratio measured by EPMA at $1050^{\circ} \mathrm{C}$.

\section{Discussion}

The deposition conditions employed in this research lead to obtaining nitrides, oxynitrides and oxides using the same experimental set up but changing the $\mathrm{N}_{2} / \mathrm{O}_{2}$ gas flow ratio introduced in the reactor. It has been observed that oxynitrides Cr-Al-O-N can be only obtained when the $\mathrm{N}_{2} / \mathrm{O}_{2}$ gas flow ratio is $95 / 5$ or larger. Below this value, oxygen is the unique anion present in the coatings. The $\mathrm{N}_{2} / \mathrm{O}_{2}$ gas flow ratio onset related to the transition between oxynitride and pure oxide, as found in this study (90/10), is larger than the value reported by Stüber et al [15] for sputtered coatings (i.e. 75/25) and the one by Khatibi et al [15], which was found at $63 / 37$. The reason for this deviation, in addition to possible standard errors of the mass flow gauges.

The qualitative evolution of the stoichiometric formulae observed in this work, i.e. from $(\mathrm{Cr}+\mathrm{Al})_{1+\varepsilon}(\mathrm{O}+\mathrm{N})_{1-\varepsilon}$ for the nitride $\mathbf{A}$ and the oxynitride $\mathbf{B}$, to a $(\mathrm{CrAl})_{2+\varepsilon} \mathrm{O}_{3-\delta}$, in the case of the oxide coatings $\mathbf{C}$ to $\mathbf{H}$, is in good agreement with previous studies [15]. Furthermore, the 
influence of oxygen in the deposition process is manifested by the observed threshold from low to high roughness, as a function of the $\mathrm{N}_{2} / \mathrm{O}_{2}$ gas flow ratio (i.e. $90 / 10$ ).

The coating nanoindentation hardness as a function of the $\mathrm{N}_{2} / \mathrm{O}_{2}$ gas flow ratio is similar to that found by Najafi et al [14] for arc deposited coatings. These authors interpreted that the decrease of the hardness was due to the larger presence of cation vacancies in the fcc lattice structures as the oxygen content increased. In fact, they observed that the hardness increased again for the corundum coatings. In the present work, the coating hardness evolution is explained, not only in terms of the variation of the stoichiometry and ratio of ionic to covalent bonds, but also considering the coating microstructure. Indeed, SEM cross section images revealed that the coating morphologies become less compact when the $\mathrm{N}_{2} / \mathrm{O}_{2}$ gas flow decreases. This is also in concordance with the observed reduction in the deposition rate due to the cathode surface poisoning. The poisoning leads to the ejection of bigger macrodroplets, thus contributing to develop coating microstructures with weaker intercolumnar cohesion.

The crystalline structures measured on the deposited coatings indicate that the cubic fcc phase is present in the oxynitride films B. This is in agreement with Najafi et al [14] and Khatibi et al [15] who reported that arc evaporated oxynitride Cr-Al-O-N coatings exhibit mainly a cubic structure. In addition, the oxide samples (i.e. $\mathbf{C}$ to $\mathbf{H}$ ) also contain a certain volume fractions of cubic phases, again in agreement with previous studies on arc evaporated $\mathrm{Cr}-\mathrm{Al}$ oxides $[9,11]$.

After thermal oxidation in air, all the tested coatings transformed from their original structures to either a single phase structure for $\mathbf{C}$ and $\mathbf{D}$ (oxide) or a double phase structure for $\mathbf{A}$ (nitride), and 
less pronounced in the case of $\mathbf{B}$ (oxynitride). The single structure formed for samples $\mathbf{C}$ and $\mathbf{D}$ after thermal annealing at $1100{ }^{\circ} \mathrm{C}$ may correspond to a solid solution of the type $\alpha-(\mathrm{CrAl})_{2} \mathrm{O}_{3}$, with a rhombohedral lattice. This is supported by the fact that the diffraction peaks lay in between the theoretical positions of the eskolaite and the corundum, and that the cation ratio $\mathrm{Cr} / \mathrm{Al}$ is preserved after annealing (cf. Table 4). According to the eskolaite-corundum equilibrium phase diagram $[12,33]$, at $1100^{\circ} \mathrm{C}$ there is still a significant miscibility gap between both phases. This means that, thermodynamically, the annealing at this temperature may lead to a segregation of the two components, to Al-containing eskolaite and Cr-containing corundum. This is compatible with the dual peak structure observed for samples of batches $\mathbf{A}$ and $\mathbf{B}$. However, such segregation is not present for the oxide samples (C-D). This could be due to the fact that the diffusion kinetics of the atomic species within the oxide coatings (C-D) during annealing is slower than those in the nitride and oxynitrides films.

The phase evolution upon the annealing temperature depends also on the coatings composition as-deposited. Nitrides and oxynitrides retain the cubic fcc diffraction peaks up to $950{ }^{\circ} \mathrm{C}$, whereas the oxide coatings do up to $1000^{\circ} \mathrm{C}$. Above these temperatures, the whole cubic structures vanish and the new rhombohedral phases show up, along with peaks from $\beta-\mathrm{Cr}_{2} \mathrm{~N}$. The advent of this $\beta$ phase has also been reported in other CrN based systems such as PVD coated CrAlSiN [34] after annealing in oxidising atmospheres. All these results are consistent with the observations of the structural evolution from the cubic fcc phases present in of both $\mathrm{Cr}-\mathrm{Al}-\mathrm{O}$ and Cr-Al-O-N coatings to rhombohedral structures (corundum, eskolaite or its solid solution), reported by other authors $[14,15,19]$. Although it should be pointed out that those test in the literature were done under inert atmospheres, either Ar or vacuum. 
The hardness evolution with the increasing temperature also showed dependencies on the film stoichiometry. The oxide samples, $\mathbf{C}$ and $\mathbf{D}$, exhibit excellent nanoindentation hardness stability up to $1100{ }^{\circ} \mathrm{C}$. On the other hand, the nitride and oxynitride coatings $\mathbf{A}$ and $\mathbf{B}$ showed larger variations of their nanoindentation hardness and reduced modulus. In fact, the indentation hardness of samples $\mathbf{C}$ and $\mathbf{D}$ reach a maximum value near $30 \mathrm{GPa}$. These high values are in agreement with a solid solution strengthened microstructure $\alpha-(\mathrm{CrAl})_{2} \mathrm{O}_{3}$, as revealed by XRD. On the other hand, the presence of dual-phases eskolaite/corundum, as observed for samples $\mathbf{A}$ and $\mathbf{B}$, might be causing that the hardness after $1100{ }^{\circ} \mathrm{C}$ annealing is lower than that of the samples $\mathbf{C}$ and $\mathbf{D}$.

\section{Conclusions}

In summary, this work provides a comprehensive evaluation of the chemical, structural and mechanical properties of CrAINO arc PVD coatings, as well as their evolution under thermal annealing in air. The coatings present compositions, microstructure and mechanical properties in line with those found for cathodic arc evaporated coatings by different authors. In particular, the $\mathrm{N}_{2} / \mathrm{O}_{2}$ flow ratio onset to form oxynitrides instead of pure oxides is slightly larger than that reported for similar coating systems. Excessive oxygen also caused the films to accumulate large amount of macro droplets, causing an abrupt increase of the film roughness when the $\mathrm{N}_{2} / \mathrm{O}_{2}$ flow passes the onset 90/10. 
The presence of nitrogen in the system $\mathrm{Cr}-\mathrm{Al}-\mathrm{O}-\mathrm{N}$ determines the stoichiometric relation and the crystalline structure. When nitrogen is incorporated in the coatings the film composition have the $(\mathrm{Cr}+\mathrm{Al})_{1+\varepsilon}(\mathrm{O}+\mathrm{N})_{1-\varepsilon}$ form, whereas it evolves to $(\mathrm{CrAl})_{2+\varepsilon} \mathrm{O}_{3-\varepsilon}$ when nitrogen is absent. The nanoindentation hardness and reduced modulus seem to depend mainly on the inter-columnar bond strength of the coating microstructure, rather than on the composition. On the other hand, the maximum values were found for the oxynitride coating, suggesting a strengthening effect due the formation of a solid solution $(\mathrm{Cr}+\mathrm{Al})_{1+\varepsilon}(\mathrm{O}+\mathrm{N})_{1-\varepsilon}$.

The annealing tests in air have revealed the influence of high temperature on the evolution of the lattice structure and hardness of the deposited coatings. The observed onset temperature for the formation of the new phases depends on the coating composition. The oxide and oxynitride coatings developed a dual structure of eskolaite and corundum, while the oxides seem to develop solid solutions of the type $\alpha-(\mathrm{CrAl})_{2} \mathrm{O}_{3}$ at high temperatures. On the other hand, the cubic phases were preserved up to $950{ }^{\circ} \mathrm{C}$ for the oxynitrides and up to $1000{ }^{\circ} \mathrm{C}$ for the oxides. Other phases, such as the $\beta-\mathrm{Cr}_{2} \mathrm{~N}$, were formed at $900{ }^{\circ} \mathrm{C}$ for the oxynitride coatings.

\section{Acknowledgements}

This work has been funded by the Spanish Ministry of Economy and Competitiveness through the project PROTEOX MAT2013-45391-P. The European Commission is also acknowledged through the FOF-NMP project MICROFAST under contract Nr 608720. The Research Group of 
Surface Engineering and Nanostructured Materials in the Universidad Complutense de Madrid also acknowledges financial support of the Spanish MINECO (project MAT2015-65539-P) and to Alfredo Fernández Larios for the EPMA analysis of the samples.

\section{References}

[1] Makoto Hirai, Hajime Saito, Tsuneo Suzuki, Hisayuki Suematsu, Weihua Jiang, Kiyoshi Yatsui. Oxidation behavior of $\mathrm{Cr}-\mathrm{Al}-\mathrm{N}-\mathrm{O}$ thin films prepared by pulsed laser deposition. Thin Solid Films 407 (2002) 122-125

[2] P. Eklund, M. Sridharan, M. Sillassen, J. Bøttiger. $\alpha-\mathrm{Cr}_{2} \mathrm{O}_{3}$ template-texture effect on $\alpha-$ $\mathrm{Al}_{2} \mathrm{O}_{3}$ thin-film growth. Thin Solid Films 516 (2008) 7447-7450

[3] Jürgen Ramm, Antonia Neels, Beno Widrig, Max Döbeli, Leandro de Abreu Vieira, Alex Dommann, Helmut Rudigier Correlation between target surface and layer nucleation in the synthesis of Al- $\mathrm{Cr}-\mathrm{O}$ coatings deposited by reactive cathodic arc evaporation. Surface \& Coatings Technology 205 (2010) 1356-1361

[4] D. Diechle, M. Stueber, H. Leiste, S. Ulrich, V. Schier. Combinatorial approach to the growth of $\alpha-\left(\mathrm{Al}_{1-\mathrm{x}}, \mathrm{Cr}_{\mathrm{x}}\right)_{2} \mathrm{O}_{3}$ solid solution strengthened thin films by reactive r.f. magnetron sputtering Surface \& Coatings Technology 204 (2010) 3258-3264

[5] A. Khatibi, J. Palisaitis, C. Höglund, A. Eriksson, P.O.Å. Persson, J. Jensen, J. Birch, P. Eklund, L. Hultman. Face-centered cubic $\left(\mathrm{Al}_{1-\mathrm{x}} \mathrm{Cr}_{\mathrm{x}}\right)_{2} \mathrm{O}_{3}$. Thin Solid Films 519 (2011) $2426-2429$.

[6] A. Larsson, S. Rupp. Microstructure and properties of CVD c-A12O3 coatings. International Journal of Refractory Metals \& Hard Materials 19 /2001) 515-522 
[7] T. Kohara, H. Tamagaki, Y. Ikari, H. Fujii, Surf. Coat. Technol. 185 (2004).

[8] K. Pedersen, J. Bøttiger, M. Sridharan, M. Sillassen, P. Eklund. Texture and microstructure of $\mathrm{Cr}_{2} \mathrm{O}_{3}$ and $(\mathrm{Cr}, \mathrm{Al})_{2} \mathrm{O}_{3}$ thin films deposited by reactive inductively coupled plasma magnetron sputtering. Thin Solid Films 518 (2010) 4294-4298.

[9] H. Najafi, A. Karimi, P. Dessarzin, M. Morstein. Formation of cubic structured $\left(\mathrm{Al}_{1-\mathrm{x}} \mathrm{Cr}_{\mathrm{x}}\right)_{2+\delta} \mathrm{O}_{3}$ and its dynamic transition to corundum phase during cathodic arc evaporation. Surface \& Coatings Technology 214 (2013) 46-52.

[10] M. Pohler, R. Franz, J. Ramm, P. Polcik, C. Mitterer. Cathodic arc deposition of $(\mathrm{Al}, \mathrm{Cr})_{2} \mathrm{O}_{3}$ : Macroparticles and cathode surface modifications. Surface \& Coatings Technology 206 (2011) 1454-1460.

[11] Jürgen Ramm, Michael Ante, Theo Bachmann, Beno Widrig, Hans Brändle, Max Döbeli. Pulse enhanced electron emission ( $\left.\mathrm{P} 3 \mathrm{e}^{\mathrm{TM}}\right)$ arc evaporation and the synthesis of wear resistant Al-Cr-O coatings in corundum structure. Surface \& Coatings Technology 202 (2007) $876-883$

[12] N. D. Chatterjee, H. Leistner, L. Terhart, K. Abraham, and R. Klaska, "Thermodynamic mixing properties of corundum-eskolaite, $\alpha-(\mathrm{Al}, \mathrm{Cr})_{2} \mathrm{O}_{3}$, crystalline solutions at high temperatures and pressures," Am. Mineral., vol. 67, p. 725, 1982.

[13] A. Khatibi, A. Genvad, E. Göthelid, J. Jensen, P. Eklund, L. Hultman. Structural and mechanical properties of corundum and cubic $\left(\mathrm{Al}_{\mathrm{x}} \mathrm{Cr}_{1-\mathrm{x}}\right)_{2+\mathrm{y}} \mathrm{O}_{3-\mathrm{y}}$ coatings grown by reactive cathodic arc evaporation in as-deposited and annealed states. Acta Materialia 61 (2013) $4811-4822$. 
[14] H. Najafi, A. Karimi, P. Dessarzin, M. Morstein. Correlation between anionic substitution and structural properties in $\operatorname{AlCr}\left(\mathrm{O}_{\mathrm{x}} \mathrm{N}_{1-\mathrm{x}}\right)$ coatings deposited by lateral rotating cathode arc PVD. Thin Solid Films 520 (2011) 1597-1602

[15] A. Khatibi, J. Sjölen, G. Greczynski, J. Jensen, P. Eklund, L. Hultman. Structural and mechanical properties of $\mathrm{Cr}-\mathrm{Al}-\mathrm{O}-\mathrm{N}$ thin films grown by cathodic arc deposition. Acta Materialia 60 (2012) 6494-6507.

[16] M. Stueber, D. Diechle, H. Leiste, S. Ulrich. Synthesis of Al-Cr-O-N thin films in corundum and f.c.c. structure by reactive r.f. magnetron sputtering. Thin Solid Films 519 (2011) 4025-4031

[17] M. Stüber, U. Albers, H. Leiste, K. Seemann, C. Ziebert, S. Ulrich. Magnetron sputtering of hard Cr-Al-N-O thin films. Surface \& Coatings Technology 203 (2008) 661-665

[18] L. de Andreu Vieira, M. Döbelo, A. Dommann, E. Kalchbrenner, A. Neels, J. Ramm, H. Rudigier, J. Thomas, B. Widrig. Surface \& Coating Technology 204 (2010)1722-1728

[19] V. Edlmayr, M. Pohler, I. Letofsky-Papst, C. Mitterer. Microstructure and thermal stability of corundum-type $\left(\mathrm{Al}_{0.5} \mathrm{Cr}_{0.5}\right)_{2} \mathrm{O}_{3}$ solid solution coatings grown by cathodic arc evaporation. Thin Solid Films 534 (2013) 373-379.

[20] A. Kayani, R.J. Smith, S. Teintze, M. Kopczyk, P.E. Gannon, M.C. Deibert, V.I. Gorokhovsky, V. Shutthanandan. Oxidation studies of CrAlON nanolayered coatings on steel plates. Surface \& Coatings Technology 201 (2006) 1685-1694

[21] E. Almandoz, J. Fernández de Ara, J. Martínez de Bujanda, J. Fernández Palacio, R. J. Rodríguez, Z. Zhang, Hanshan Dong, Yi Qin, G. G. Fuentes. CrAlON CAE-PVD coatings for oxidation and wear protection of TZM alloys in FAST sintering applicationsMaterials Chemistry and Physics 208 (2018) 189-197 
[22] H.D. Liu, T.R.Fu, M.H.Duan, Q.Wan, C.luo, Y.M.Chen, D.J.Fu, F.Ren, Q.Y.Li, X.D. Cheng, B.Yang, X.J.Hu. Structure and thermal stability of spectrally selective absorber based on AlCrON coating for solar-thermal conversion applications. Solar Energy Materials \& Solar Cells157(2016)108-116.

[23] Jiri Nohava, Pascal Dessarzin, Pavla Karvankova, Marcus Morstein. Characterization of tribological behavior and wear mechanisms of novel oxynitride PVD coatings designed for applications at high temperatures. Tribology International 81 (2015) 231-239.

[24] K. Bobzin, T. Brögelmann, C. Kalscheuer, T. Liang. Surface Coating Technology 322 (2017) 152-162.

[25] Koller, C.M., Glatz, S.A., Kolozsvári, S., Ramm, J., Mayrhofer, P.H.. Influence of substrate bias on structure and mechanical properties of arc evaporated $(\mathrm{Al}, \mathrm{Cr})_{2} \mathrm{O}_{3}$ and $(\mathrm{Al}, \mathrm{Cr}, \mathrm{Fe})_{2} \mathrm{O}_{3}$ coatings. Surface and Coatings Technology, 319 (2017) 386-393

[26] Pohler, M., Franz, R., Ramm, J., Polcik, P., Mitterer, C. Influence of pulsed bias duty cycle variations on structural and mechanical properties of arc evaporated $(\mathrm{Al}, \mathrm{Cr})_{2} \mathrm{O}_{3}$ coatings. Surface and Coatings Technology, 282 (2015) 43-51

[27] J. Fernández de Ara, E. Almandoz, J. F. Palacio, G. G. Fuentes, R. J. Rodríguez, and J. A. García. Influence of temperature in arc-activated plasma nitriding of maraging steel in solution annealed and aged conditions. Surf. Coatings Technol. 258 (2014) 754-762.

[28] W. Oliver, G. Pharr, Journal of Materials Research 19 (1) (2004) 3-20.

[29] G. Alcala, S. Mato, P. Skeldon, G.E. Thompson, A.B. Mann, H. Habazaki, K. Shimizu. Mechanical properties of barrier-type anodic alumina films using nanoindentation. Surface and Coatings Technology 173 (2003) 293-298. 
[30] A. Georgiadis, G. G. Fuentes, E. Almandoz, A. Medrano, J. F. Palacio, A. Miguel. Materials Chemistry and Physics 190 (2017) 194-201

[31] T. Polcar, A. Cavaleiro. High-temperature tribological properties of CrAlN, CrAlSiN and AlCrSiN coatings. Surface and Coatings Technology 206 (2011) 1244-1251.

[32] Xin Ren, Fuhui Wang, Xin Wang High-temperature oxidation and hot corrosion behaviors of the NiCr-CrAl coating on a nickel-based superalloy. Surface and Coatings Technology $198,(2005) 425-431$

[33] T.M. Besmann, N.S. Kulkarni, K.E. Spear. Thermochemical analysis and modeling of the $\mathrm{Al}_{2} \mathrm{O}_{3}-\mathrm{Cr}_{2} \mathrm{O}_{3}, \mathrm{Cr}_{2} \mathrm{O}_{3}-\mathrm{SiO}_{2}$, and $\mathrm{Al}_{2} \mathrm{O}_{3}-\mathrm{Cr}_{2} \mathrm{O}_{3}-\mathrm{SiO}_{2}$ systems relevant to refractories. J.American Ceramic Society 89 (2006) 638-644.

[34] T. Polcar, A. Cavaleiro. High temperature properties of CrAlN, CrAlSiN and AlCrSiN coatings - Structure and oxidation. Materials Chemistry and Physics 129 (2011) 195-201

\section{TABLE 1}

\section{CrAIN adhesion layer}

\begin{tabular}{cr}
\hline Cr50-Al50 arc current $(\mathrm{A})$ & 60 \\
Substrate Bias $(\mathrm{V})$ & -50 \\
Pressure $\mathrm{N}_{2}(\mathrm{~Pa})$ & 1.8 \\
Deposition CrAlON films & \\
\hline Cr50-Al50 arc current $(\mathrm{A})$ & 60 \\
Substrate Bias $(\mathrm{V})$ & -50 \\
Pressure $\mathrm{N}_{2}+\mathrm{O}_{2}(\mathrm{~Pa})$ & 1.8 \\
Temperature ${ }^{\circ} \mathrm{C}$ & $410-430$ \\
\hline
\end{tabular}

* Sample batch $\mathrm{H}$ of Table 2 was coated at $-200 \mathrm{~V}$ substrate BIAS 
TABLE 2

\begin{tabular}{|cclcc|}
\hline Sample & $\mathbf{O}_{2} / \mathbf{N}_{2}$ gas flow & Stoichiometry & $\begin{array}{c}\% \mathbf{i n}(\mathbf{C r}+\mathbf{A l}) 1-\mathbf{x} \\
\left(\left(\mathbf{O}_{2}+\mathbf{N}_{2}\right) \mathbf{x}\right.\end{array}$ & $\begin{array}{c}\text { Thickness } \\
(\mu \mathrm{m})\end{array}$ \\
\hline $\mathrm{A}$ & $0 / 100$ & $\mathrm{Cr}_{0.32} \mathrm{Al}_{0.31} \mathrm{O}_{0.02} \mathrm{~N}_{0.34}$ & $36 \%$ & $2.59 \pm 0.03$ \\
$\mathrm{~B}$ & $5 / 95$ & $\mathrm{Cr}_{0.25} \mathrm{Al}_{0.23} \mathrm{O}_{0.30} \mathrm{~N}_{0.22}$ & $52 \%$ & $2.33 \pm 0.14$ \\
$\mathrm{C}$ & $10 / 90$ & $\mathrm{Cr}_{0.22} \mathrm{Al}_{0.19} \mathrm{O}_{0.59}$ & $59 \%$ & $2.35 \pm 0.12$ \\
$\mathrm{D}$ & $25 / 75$ & $\mathrm{Cr}_{0.20} \mathrm{Al}_{0.19} \mathrm{O}_{0.61}$ & $61 \%$ & $2.37 \pm 0.04$ \\
$\mathrm{E}$ & $37 / 63$ & $\mathrm{Cr}_{0.22} \mathrm{Al}_{0.16} \mathrm{O}_{0.62}$ & $62 \%$ & $2.12 \pm 0.04$ \\
$\mathrm{~F}$ & $75 / 25$ & $\mathrm{Cr}_{0.20} \mathrm{Al}_{0.19} \mathrm{O}_{0.61}$ & $61 \%$ & $2.27 \pm 0.05$ \\
$\mathrm{G}$ & $100 / 0$ & $\mathrm{Cr}_{0.22} \mathrm{Al}_{0.20} \mathrm{O}_{0.58}$ & $58 \%$ & $2.04 \pm 0.09$ \\
$\mathrm{H}^{*}$ & $37 / 63$ & $\mathrm{Cr}_{0.22} \mathrm{Al}_{0.21} \mathrm{O}_{0.57}$ & $57 \%$ & $2.12 \pm 0.03$ \\
\hline
\end{tabular}

* Sample $\mathrm{H}$ is carried out at a BIAS of $-200 \mathrm{~V}$. 
TABLE 3

\begin{tabular}{|c|c|c|c|c|c|c|}
\hline Sample & Stoichiometry & $\mathrm{Ra}(\mathrm{nm})$ & $\mathrm{Rq}(\mathrm{nm})$ & $H(G P a)$ & $E(G P a)$ & $H / E$ \\
\hline A & $\mathrm{Cr}_{0.32} \mathrm{Al}_{0.31} \mathrm{O}_{0.02} \mathrm{~N}_{0.34}$ & $\begin{array}{l}55.2 \pm \\
4.7\end{array}$ & $118 \pm 14$ & $23.3 \pm 5.5$ & $202 \pm 10$ & 0.115 \\
\hline $\mathrm{B}$ & $\mathrm{Cr}_{0.25} \mathrm{Al}_{0.23} \mathrm{O}_{0.30} \mathrm{~N}_{0.22}$ & $\begin{array}{l}55.4 \pm \\
2.4\end{array}$ & $124 \pm 6$ & $28.8 \pm 2.6$ & $187 \pm 8$ & 0.154 \\
\hline C & $\mathrm{Cr}_{0.22} \mathrm{Al}_{0.19} \mathrm{O}_{0.59}$ & $\begin{array}{c}46.7 \pm \\
2.4\end{array}$ & $120 \pm 14$ & $27.1 \pm 1.6$ & $174 \pm 17$ & 0.156 \\
\hline$D$ & $\mathrm{Cr}_{0.20} \mathrm{Al}_{0.19} \mathrm{O}_{0.61}$ & $\begin{array}{c}103.7 \pm \\
2.7\end{array}$ & $185 \pm 7$ & $24.5 \pm 2.2$ & $195 \pm 8$ & 0.126 \\
\hline$E$ & $\mathrm{Cr}_{0.22} \mathrm{Al}_{0.16} \mathrm{O}_{0.62}$ & $\begin{array}{l}93.3 \pm \\
3.8\end{array}$ & $160 \pm 4$ & $21.3 \pm 3.5$ & $183 \pm 9$ & 0.116 \\
\hline $\mathrm{F}$ & $\mathrm{Cr}_{0.20} \mathrm{Al}_{0.19} \mathrm{O}_{0.61}$ & $\begin{array}{c}107.8 \pm \\
4.3\end{array}$ & $196 \pm 29$ & $16.1 \pm 3.2$ & $177 \pm 9$ & 0.097 \\
\hline$G$ & $\mathrm{Cr}_{0.22} \mathrm{Al}_{0.20} \mathrm{O}_{0.58}$ & $\begin{array}{l}78.7 \pm \\
1.9\end{array}$ & $151 \pm 6$ & $18.6 \pm 3.1$ & $166 \pm 12$ & 0.106 \\
\hline $\mathrm{H}^{*}$ & $\mathrm{Cr}_{0.22} \mathrm{Al}_{0.21} \mathrm{O}_{0.57}$ & $112 \pm 6$ & $199 \pm 25$ & $26.8 \pm 2.8$ & $201 \pm 6$ & 0.133 \\
\hline
\end{tabular}

TABLE 4

\begin{tabular}{|c|c|c|c|c|}
\cline { 2 - 5 } \multicolumn{1}{c|}{} & \multicolumn{2}{c|}{$\left(\mathrm{Cr}_{1-\mathrm{x}} \mathrm{Al}_{\mathbf{x}}\right)_{2+\mathrm{y}} \mathrm{O}_{3-\mathrm{y}}$} & \multicolumn{2}{c|}{ Thickness $(\boldsymbol{\mu m})$} \\
\hline Sample & $\mathbf{R T}$ & $\mathbf{1 0 5 0}^{\circ} \mathbf{C}$ & $\mathbf{R T}$ & $\mathbf{1 0 5 0 ^ { \circ } \mathbf { C }}$ \\
\hline $\mathrm{A}$ & $\left(\mathrm{Cr}_{0.52} \mathrm{Al}_{0.48}\right)_{1}\left(\mathrm{O}_{0.05} \mathrm{~N}_{0.95}\right)_{0.57}$ & $\left(\mathrm{Cr}_{0.32} \mathrm{Al}_{0.68}\right)_{2.23} \mathrm{O}_{2.77}$ & $2.59 \pm 0.03$ & $2.43 \pm 0.09$ \\
$\mathrm{~B}$ & $\left(\mathrm{Cr}_{0.52} \mathrm{Al}_{0.48}\right)_{0.96}\left(\mathrm{O}_{0.52} \mathrm{~N}_{0.48}\right)_{1.04}$ & $\left(\mathrm{Cr}_{0.51} \mathrm{Al}_{0.49}\right)_{1.98} \mathrm{O}_{3.02}$ & $2.33 \pm 0.14$ & $2.55 \pm 0.05$ \\
C & $\left(\mathrm{Cr}_{0.54} \mathrm{Al}_{0.46}\right)_{2.07} \mathrm{O}_{2.93}$ & $\left(\mathrm{Cr}_{0.61} \mathrm{Al}_{0.39}\right)_{1.93} \mathrm{O}_{3.07}$ & $2.35 \pm 0.12$ & $2.09 \pm 0.13$ \\
D & $\left(\mathrm{Cr}_{0.52} \mathrm{Al}_{0.48}\right)_{1.96} \mathrm{O}_{3.04}$ & $\left(\mathrm{Cr}_{0.53} \mathrm{Al}_{0.47}\right)_{1.98} \mathrm{O}_{3.02}$ & $2.37 \pm 0.04$ & $2.15 \pm 0.10$ \\
G & $\left(\mathrm{Cr}_{0.52} \mathrm{Al}_{0.48}\right)_{2.11} \mathrm{O}_{2.89}$ & $\left(\mathrm{Cr}_{0.5} \mathrm{Al}_{0.5}\right)_{1.94} \mathrm{O}_{3.06}$ & $2.04 \pm 0.09$ & $1.73 \pm 0.16$ \\
\hline
\end{tabular}


Figure 1
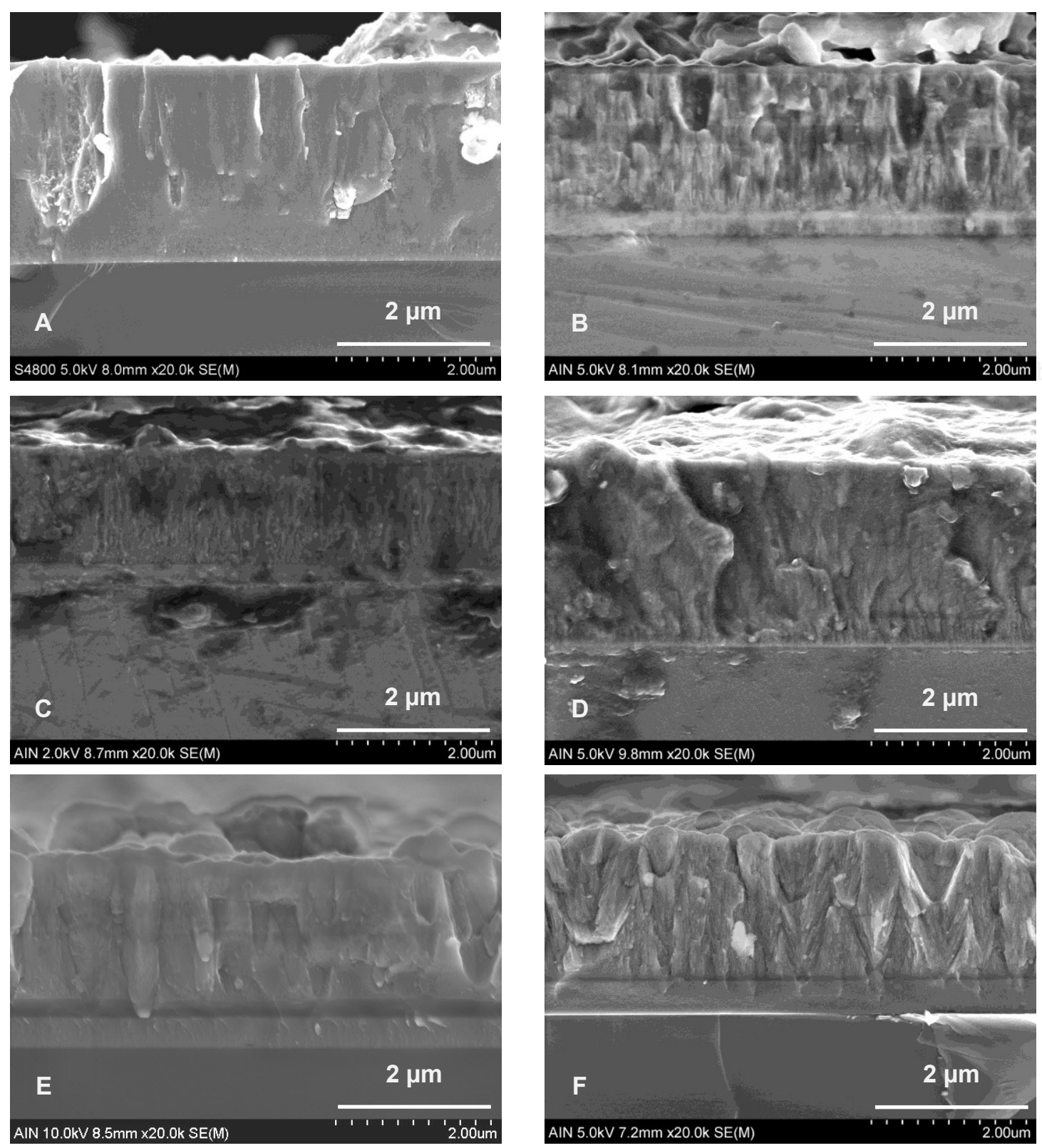

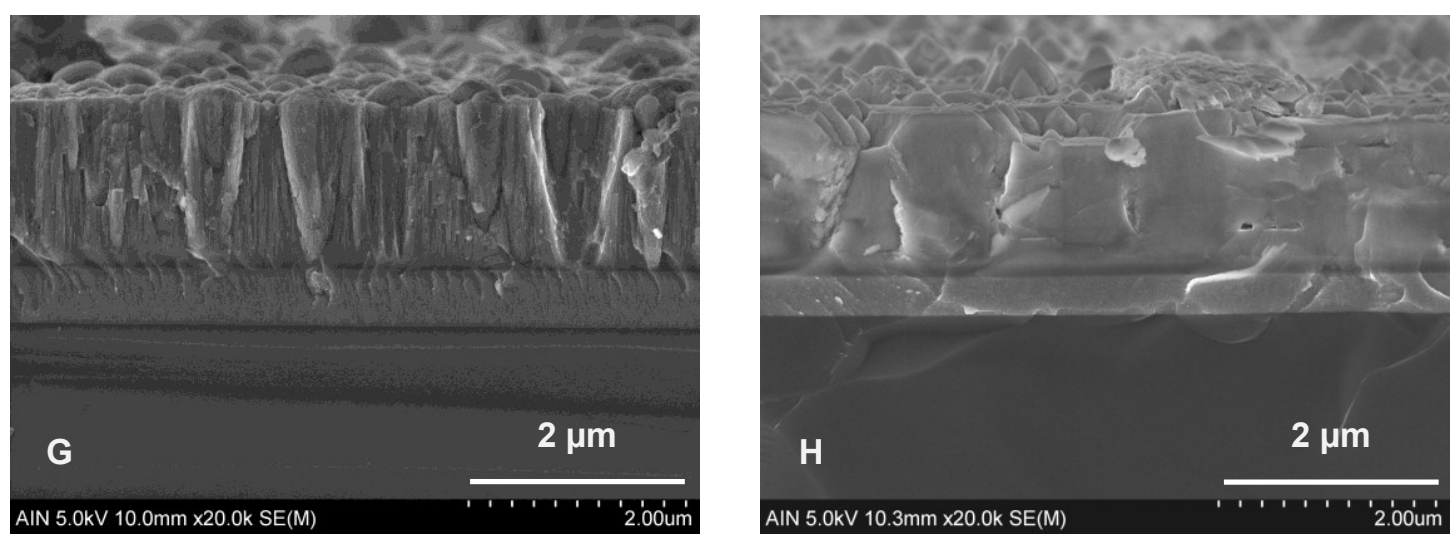
Figure 2

- h-AIN $\otimes$ fcc-CrAIN / fcc- $(\mathrm{CrAl})_{2} \mathrm{O}_{3} \bullet \alpha-(\mathrm{Cr}, \mathrm{Al})_{2} \mathrm{O}_{3}$ ?

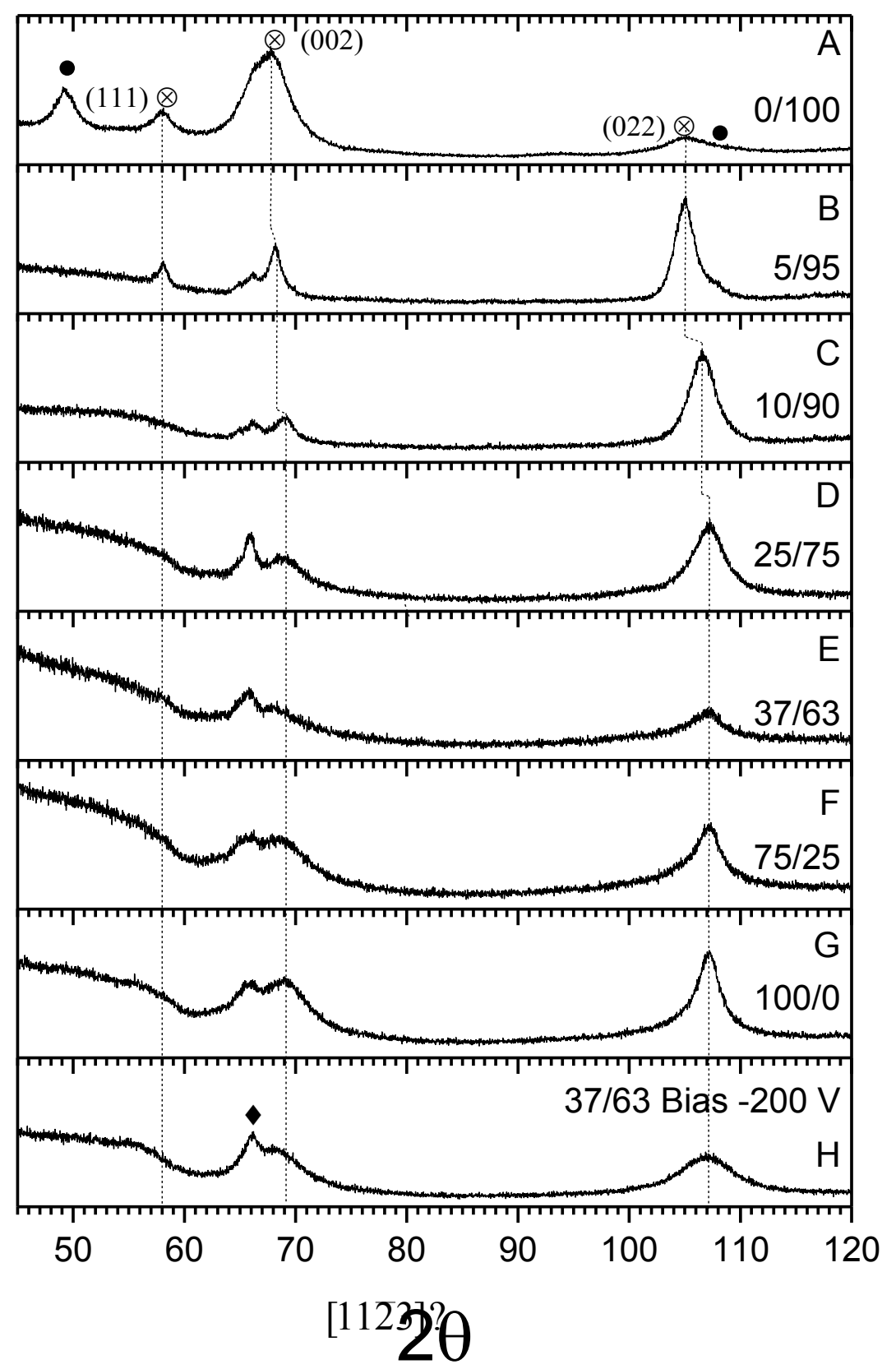


Figure 3

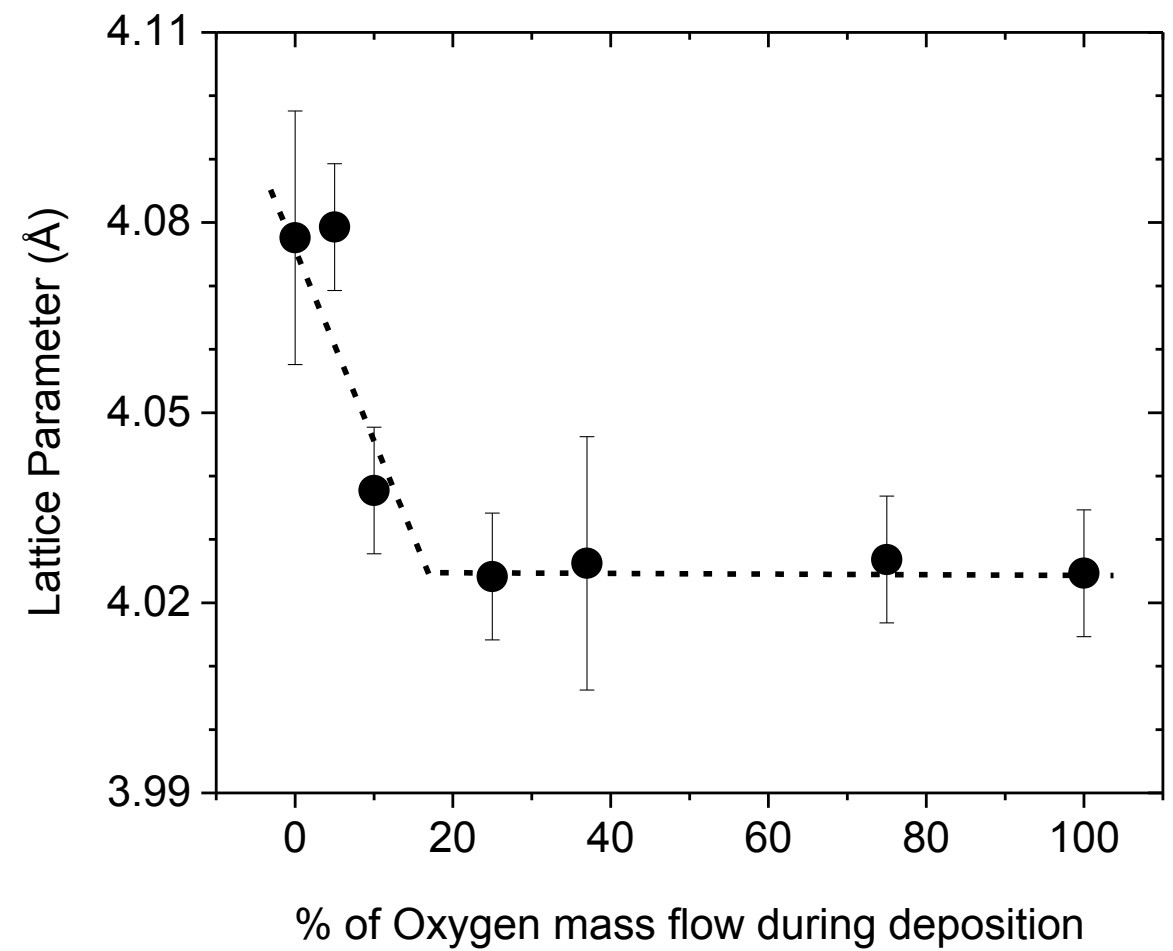


Figure 4

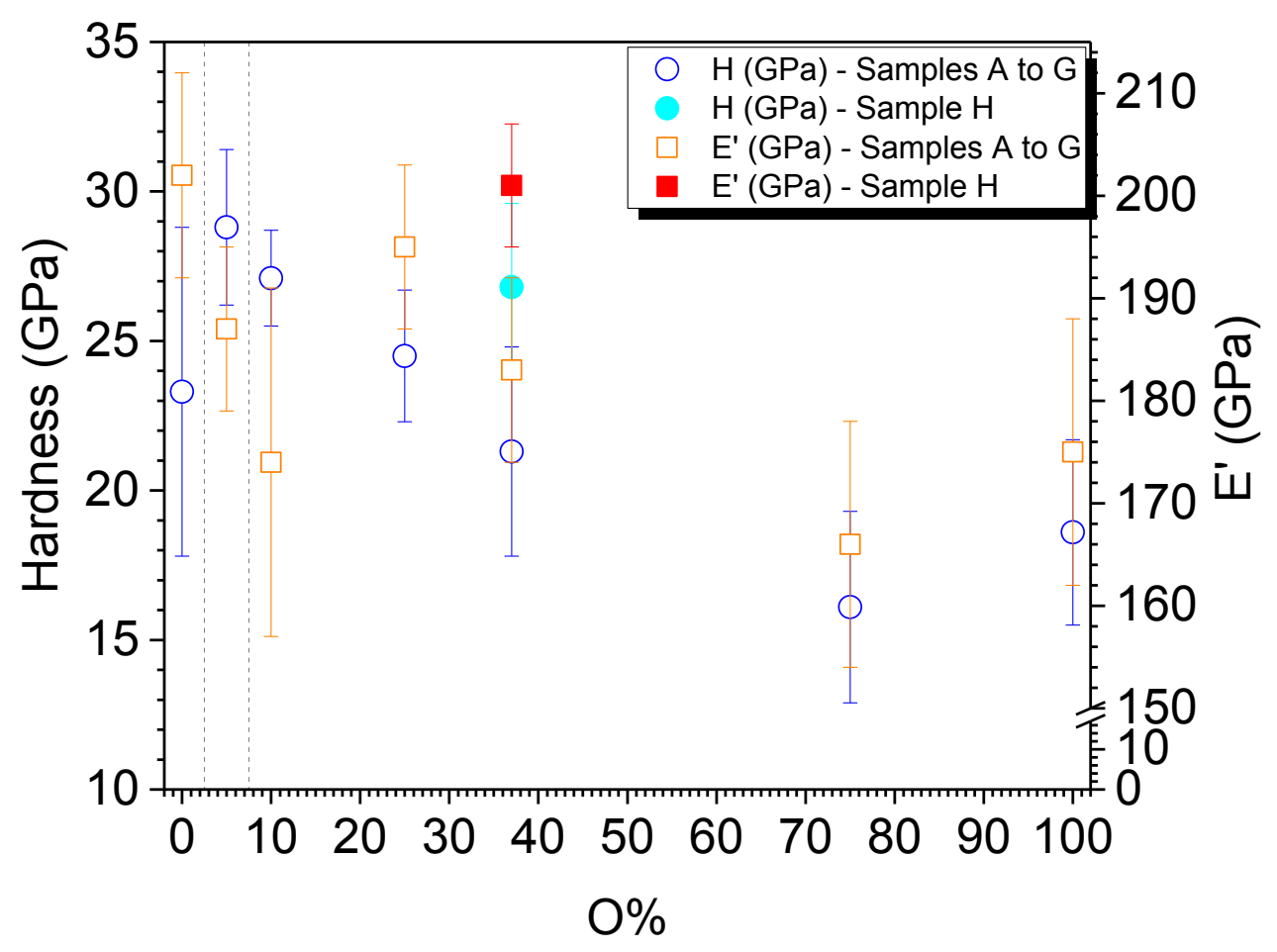


Figure 5
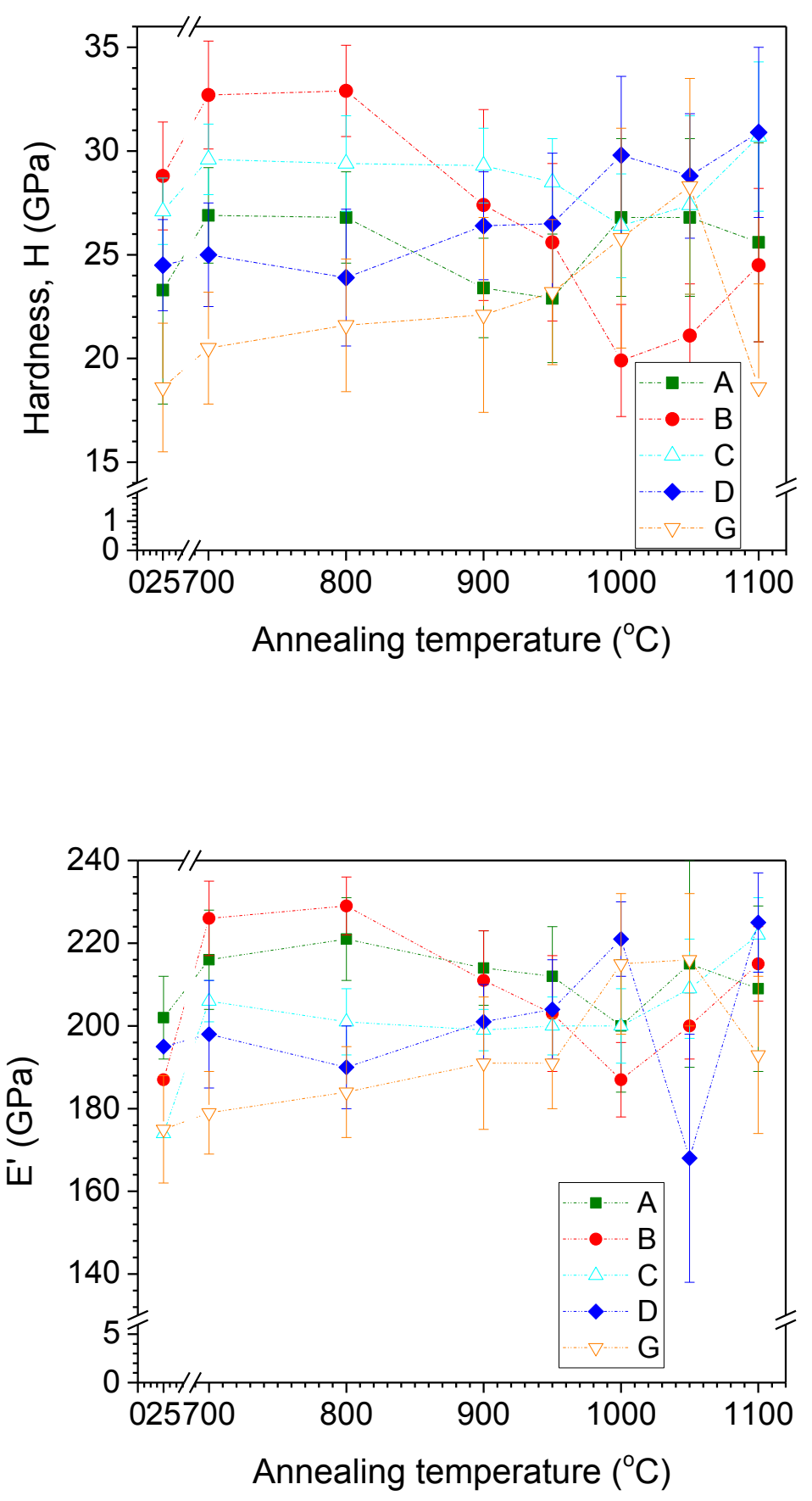
Figure 6
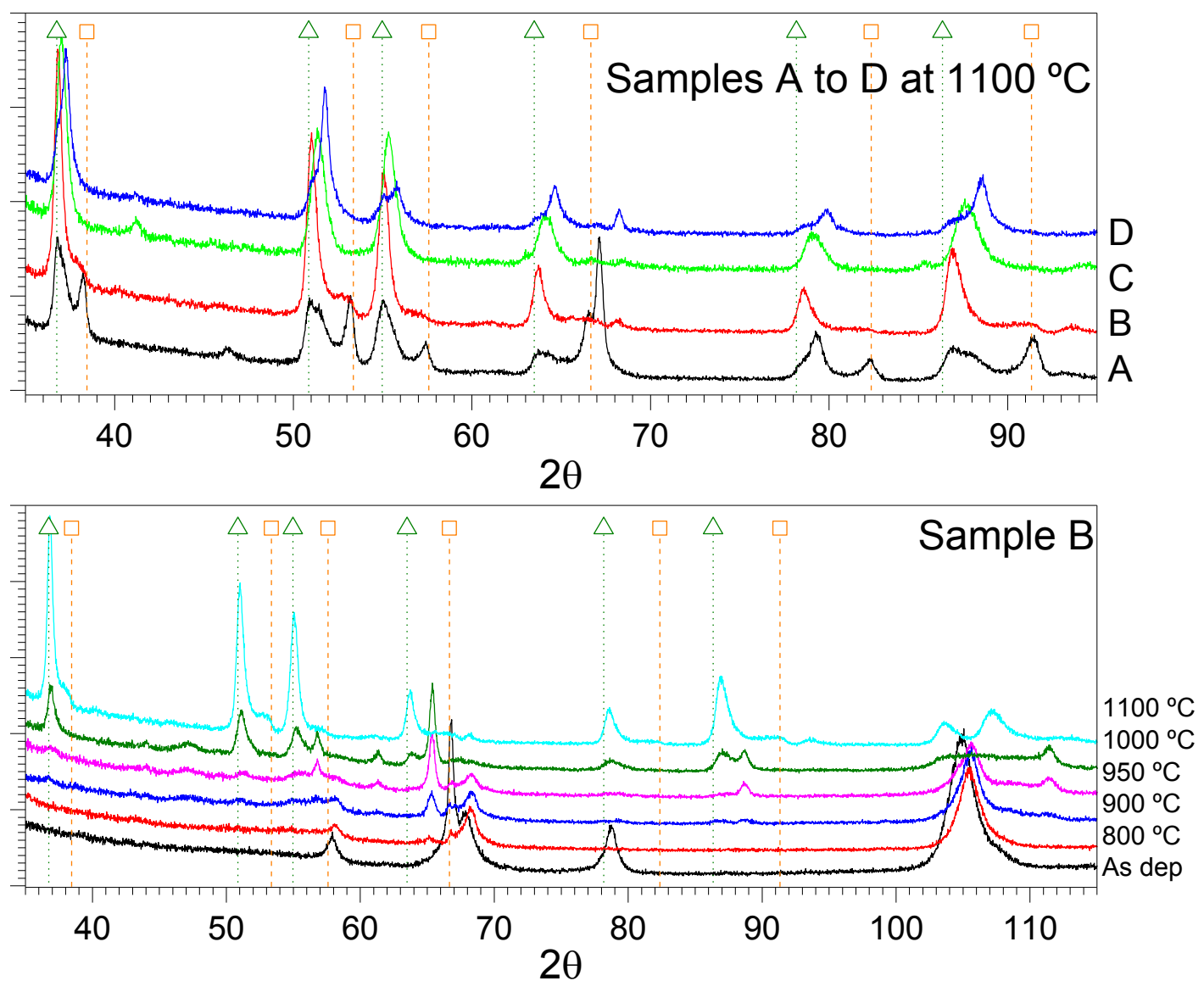

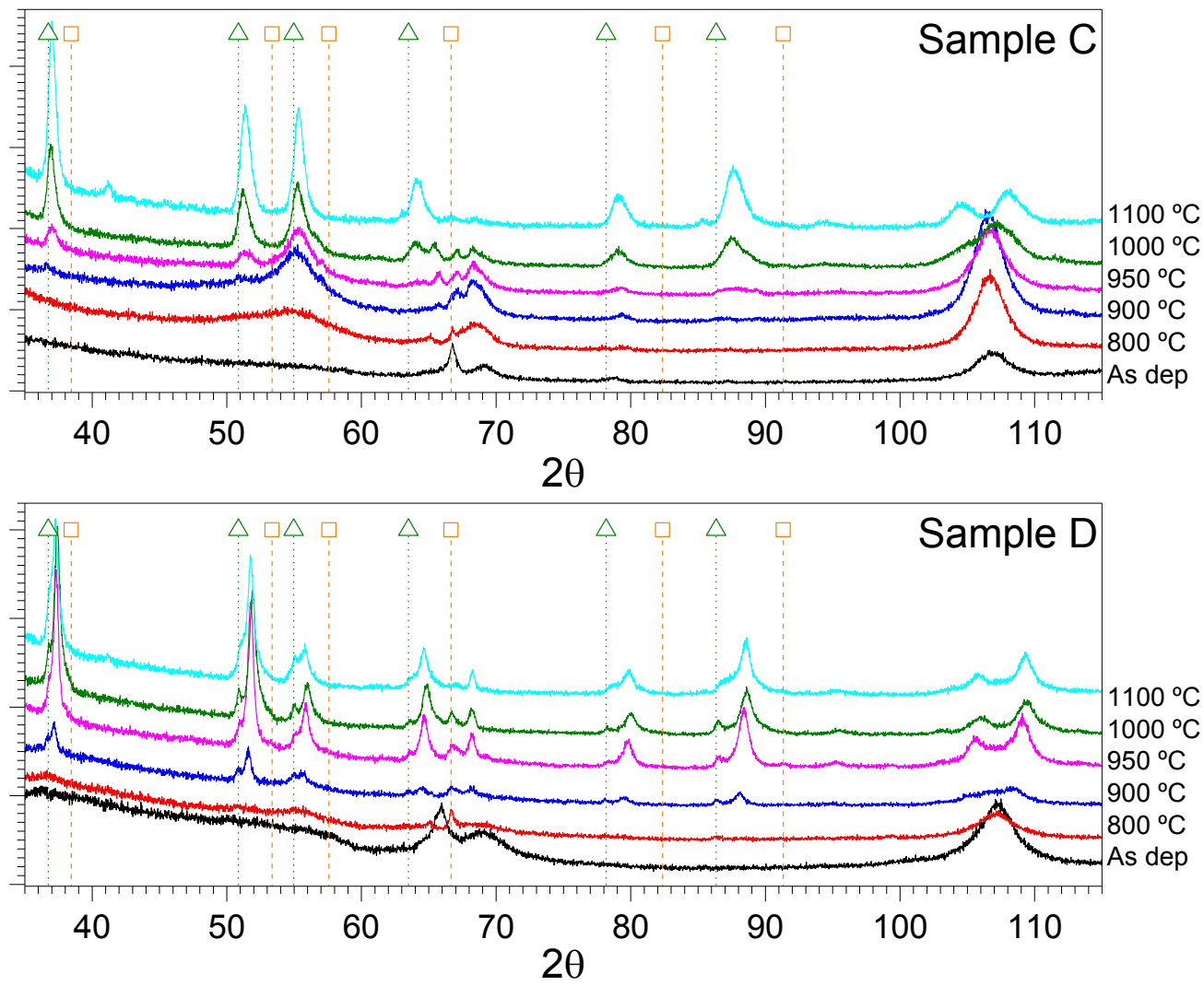